\title{
Benzoic Acid Isolation from Frankincense
}

\author{
Elferida Sormin ${ }^{1 *}$, Nelius Harefa ${ }^{2}$, Leony Sanga Lamsari Purba ${ }^{3}$, Sumiyati $^{4}$, \\ Bernadetha Nadeak ${ }^{5}$
}

\author{
1,2,3,4 Chemistry of Education, Universitas Kristen Indonesia, Cawang, Jakarta, Indonesia \\ ${ }^{5}$ Educational Administration Department, Universitas Kristen Indonesia, Cawang, Jakarta, Indonesia \\ Corresponding Email: elferida.sormin@uki.ac.id
}

\begin{abstract}
The purpose of this study was to determine whether benzoic acid can be isolated from Frankincense by using safonification method followed by hydrolysis. The Frankincense sample used is Tapanuli Frankincense, also known as Frankincense Toba or more commonly called Haminjon. Furthermore, the results obtained are identified through chemical tests and physical tests, and to ensure that the results obtained are benzoic acid spectra tests are carried out using infrared spectroscopy (IR). The results obtained are $5.29 \%$ white crystals which based on the analysis results have a melting point of 121.2-1230C and infrared absorption data shows the data at v (cm-1): $3100-2700$ (strong band) is a bound $\mathrm{OH}$ group; $1720-1690$ (strong band) is a $\mathrm{C}=\mathrm{O}$ group; $1650-1520$ (weak band) is $\mathrm{C}$ $=\mathrm{C}$ aromatic; 1275 (medium band) is $\mathrm{C}-\mathrm{O}$ carboxylic acid and 882.6-715 (medium band) is aromatic C-H out of the plane, so it is concluded that the white crystal obtained is benzoic acid as much as $5.29 \%$.
\end{abstract}

\section{Keywords: Tapanuli Frankincense, Safonification, Isolated, Benzoic Acid, Haminjon}

\section{INTRODUCTION}

Indonesia has abundant natural resources with all its diversity. There are various kinds of plants that have very high economic value, such as spices, Frankincense and also other plants that have a medicinal function. Frankincense is a unique plant and as a whole the tree has a function or use, starting from the roots, stems, leaves and also the sap almost all of which have uses. In Indonesia, Frankincense plants have long been cultivated. The area that most cultivates Frankincense is North Sumatra, specifically North Tapanuli.

Frankincense tree cultivation in the Tapanuli area, North Sumatra province is known for a long time, which is expected to begin late the 1800 s which began in the Nai Pospos and Silindung areas. The creation of the Frankincense tree plantations begins with planting sugar cane and sweet potatoes, then plant rice and seedlings of the Frankincense. At the time of harvest the young rainy rice tree has begun to grow which is then maintained by only cleaning the bushes surrounding. The Frank Frankincense Tree after being aged 5-6 years already began to be tapped for the sap taken. (Jayusman, 2014). Besides some of the above areas, there are several other areas in North Tapanuli which are also Frankincense producing areas, namely Garoga and Pangaribuan.

The Frankincense tree has important economic value, this can seen from the width of the Frankincense gardens found in several regionsin North Sumatra, mainly in the Tapanuli region. Statistical Data (2002)shows that North Tapanuli has a large area of the Frankincense garden covering an area of 22,670 ha with a production of $321.3 \mathrm{~kg} \mathrm{/} \mathrm{ha} \mathrm{/} \mathrm{year} \mathrm{with}$ productiona total of 4,247 tons / year. North Sumatra BPS data (2008) broad the largest Frankincense estate is located in North Tapanuli Regency $(16,359 \mathrm{Ha})$ and Kab. Humbahas (9,594 Ha). Exploitation of Frankincense plantationat least 60,209 families (214,000 people) have been involved the total population of North Tapanuli is 705,432.

Frankincense sap production tends to decrease and productivity is low. This matter because management is still done traditionally. Quality incense sap traded in Sumatra does not yet have a standard generally accepted, both in trader and exporter transactions. National Standards Indonesia (SNI) regarding the Ministry of Defense was compiled because of the required quality requirements frankincense sap in order to keep abreast of market developments and is quite high food Technology.

The sap of Frankincense is very a little consumed directly in North Sumatra, the consumer is located outside the central Frankincense, among others, Central Java Province (Purworejo, Kebumen, Banyumas, Cilacap, Probolinggo and Magelang), East Java (Bojonegoro, Temanggung and Wonosobo), transmigration areas and overseas (export). Use of Frankincense in several areas especially for siong cigarettes, klembak and incense materials. Country the 
main export destinations of Frankincense are Singapore, Switzerland, Japan, Malaysia, the Emiart Arab Union (UAE), Taiwan, France and so on. Singapore is more a role as a "transit" country before it flows to country of destination. The average export of Frankincense through the port entrance BelawanMedan is estimated to reach 690,411 tons per year. Value the money from the export of Frankincense varies greatly with Singapore, Taiwan, the UAE and Malysia earn US \$ 2 to US \$ 5 perkilograms, but France is higher up to US $\$ 23.9 \mathrm{~kg}$. Condition this is inseparable from the influence of not yet standard quality and price standards basic sap of Frankincense and potentially detrimental to the state and farmers Frankincense itself, but profitable for traders. Settling up these aspects and improvement of the Frankincense trade system are very important do.(Jayusman, 2014)

In the sap of Frankincense there are several ingredients, among others Sinamat Acid $\left(\mathrm{C}_{6} \mathrm{H}_{5} \mathrm{CH}-\right.$ $\mathrm{CHOOH})$, Benzoic acid, Styrol, Vanillin $\left(\mathrm{C}_{8} \mathrm{H}_{8} \mathrm{O}_{3}\right)$, Styracin, Coniferil benzoate, Coniferil sinamate, Resin benzoeresinol and resinotannol sum. (Khan, 2001).

Some researchers have tried to analyze various things about the incense, including some who isolate cinnamic acid from various qualities of Sumatran incense from Sumatra which found that the quality of incense affects the levels of cinnamic acid contained therein, where for quality I to IV contains levels cinnamic acid is relatively higher compared to other qualities. (Waluyo, 2007). Some even study specifically about the phenology of flowering and fruiting of Frankincense Toba.

In addition to cinnamic acid and several other compounds contained in frankincense, there are benzoic acids which have very many functions in daily life, for example, used as preservatives in food or drinks. Therefore, in this research will be carried out isolation of benzoic acid contained in frankincense, specifically incense of Tapanuli.

Benzoic acid, $\mathrm{C}_{7} \mathrm{H}_{6} \mathrm{O}_{2}$ (or $\mathrm{C}_{6} \mathrm{H}_{5} \mathrm{COOH}$ ), is a white crystalline solid and is an acid the simplest aromatic carboxylate. The name of this acid comes from gum benzoin (gum frankincense), which used to be the only source of benzoic acid. This weak acid along with its derived salt used as a food preservative. Benzoic acid is an important precursor in many synthesis other chemicals. Benzoic acid was first discovered in the 16th century. First distillation of dried incense described by Nostradamus (1556), and subsequently by Alexius Pedemontanus (1560) and Blaisede Vigenère (1596). Justus von Liebig and Friedrich Wöhler managed to determine the structure of benzoic acid in 1832. They also examined how hipuric acid related to benzoic acid. On in 1875, Salkowski discovered that benzoic acid had antifungal activity. Benzoic acid compounds and their salts are more widely used as food preservatives. As a preservative, benzoic acid and sodium benzoate will be effective if used in the range $\mathrm{pH} 2.5$ - 4 and become less effective when used at $\mathrm{pH}$ above 4.5 (Firdaus, F., 2017)

\section{METHOD}

The incense sample in this research is the incense from North Tapanuli, precisely from the village of Garoga, which is called the Sidukkapi Frankincense. The method used in this isolation process is the saponification method followed by hydrolysis, then the hydrolysis results are identified to determine purity through structural tests using infrared spectroscopy.

The tools used in this research are mortal, rotary evaporator, analytical balance, oven, melting point apparatus, electric bath, reflux apparatus, $\mathrm{pH}$ indicator, separating funnel, and other glassware, while the ingredients used are refined sidukkapi incense, ethanol, potassium hydroxide, $25 \%$ sulfuric acid, diethyl ether and distilled water.

work procedures carried out during the study are, Isolation Phase, among others: 1) smoothing incense and weighed to be 103.42 grams of sample, 2) incense dissolved in $230 \mathrm{~mL}$ ethanol, then filtered, 3) Filtrate obtained using rotary evaporator on a temperature of 85 $\mathrm{oC}$ until a concentrated solution is obtained (the ethanol solvent is expected to have evaporated), 4) $160 \mathrm{~mL}$ $\mathrm{KOH} 2 \mathrm{M}$ added to the concentrated solution in ethanol and stirred until all are mixed, then a $\mathrm{pH}$ measurement is taken, 5) The mixture is refluxed at $80 \mathrm{oC}$ for 2 hours and the excess solvent is evaporated, 6) After it is cold, the formed salt is dissolved in water. Water was added until all salts were estimated to dissolve, 7) $25 \%$ sulfuric acid was added to accelerate hydrolysis of the salt, 8) crystals formed after hydrolysis were separated using diethyl ether, 9) then the crystals obtained were filtered and dried. Recrystallization the work step is recrystallization, the steps of work are 1) Crystals that have been dried are recrystallized using hot water, 2) Then filtered in a hot state and filter paper washed with hot water, 3) The solution is allowed to cool to room temperature, 4) If the color of the crystal is still not white, then recrystallization process is done using sufficient activated carbon, 5) Then the crystals are dried and weighed to a constant weight. Identification Test, the work step is 1) test for the presence of benzoic acid. For this step, approximately $100 \mathrm{mg}$ of crystal is 
dissolved in $5 \mathrm{~mL}$ ethanol and then filtered. Add 0.5 $1 \mathrm{~mL} \mathrm{FeCl} 3$ to ethanol in the filtrate, if a yellowish brown is formed, then the crystal is positive containing benzoic acid; 2) physical test. for this step, the obtained crystal is inserted into the capillary tube until the pipe is fully filled and solid, then the capillary tube containing the crystal is inserted into the melting point apparatus to test its melting point. Spectroscopy Test, this phase is to find out the functional groups of the crystal content obtained

\section{RESULT AND DISCUSSION}

107.23 grams of dry crude coarse mashed using mortal. Then filtered to remove impurities. From the results obtained smooth refinement as much as 103.42 grams. When $230 \mathrm{~mL}$ of $98.8 \%$ ethanol are added, the fine incense dissolves quickly and the resulting color of the solution is golden yellow.

The yellow packaging solution is filtered using a buchner funnel, which aims to speed up the separation of impurities that are still present in the sample. The residue contained in filter paper is then weighed and obtained as much as 1.02 grams of residue, which means incense used for the next process is $103.42-1.02=102.40$ grams. Then this solution is evaporated at a temperature of $65-800 \mathrm{C}$ until the solvent does not drip again and obtained a solution that is increasingly concentrated golden yellow.

In the saponification process, the use of a $2 \mathrm{M} \mathrm{KOH}$ solvent is because the solution has a very strong appeal to all types of carboxylic acids to form alkali carboxylates in the form of salt. That reaction is:

\section{$\mathrm{R}^{-} \mathrm{CO}^{-} \mathrm{OH}+\mathrm{K}^{+} \mathrm{OH}^{-} \rightarrow \mathrm{R}^{-} \mathrm{CO}^{-} \mathrm{OK}$}

The reflux process at a temperature of $80^{\circ} \mathrm{C}$ with 2 hours aims so that the added $\mathrm{KOH}$ base can bind all the acid content contained in the incense, thus producing a lot of salt. The temperature and duration of the process used are intended so that the salt produced is not damaged and also does not decrease in amount as a result of evaporation that occurs from the temperature and the length of heating. This method is generally used to synthesize volatile compounds volatile. In this condition, if the heating is normal, the solvent will evaporate before the reaction walk to completion. The principle of the reflux method is that the volatile solvent used will evaporate at high temperatures, but will be cooled with a condenser so that the solvent was in the form
The vapor will condense on the condenser and drop back into the reaction container so that the solvent will remain present during the reaction. (Firdaus F., 2017)

During the hydrolysis process, $500 \mathrm{~mL}$ of distilled water is added until all salts are confirmed to be dissolved, from this process a milky white color is obtained, and after a long time it dissolves again. To accelerate the hydrolysis process, $25 \%$ sulfuric acid is added by as much as $50 \mathrm{~mL}$, at this time two phases of solution are formed (the upper phase is yellow solution, and the lower phase is rubber-shaped brown precipitate which should be white crystal.

After a closer observation it was found that the $\mathrm{pH}$ of the solution contained in the upper phase reached 1 and the lower phase could not be measured for its $\mathrm{pH}$ because it was in the form of rubber. Then the trial was carried out again by taking the brown sediment and adding $\mathrm{KOH}$ again, the results obtained were white crystals formed.

The crystals that are formed are macerated using diethyl ether, then the crystals are dried. The crystals obtained are not yet pure, therefore recrystallization is necessary. In the process of recrystallization the solvent used is hot water, which is added until the crystals completely dissolve. At room temperature cleaner white crystals will form again. However, this did not happen in this study, after waiting for room temperature, crystals were not formed. Therefore, then heating is done by using an oil bath with the aim to vaporize most of the solvents (water). After that, it is cooled down suddenly (when hot temperature is directly put into a container filled with ice), in the process of forming white crystals which are then filtered, dried and then weighed and obtained as much as 5.42 grams of crystals.

The percentage of crystals obtained can be calculated using the below formula:

$$
\begin{aligned}
& \text { percentage of benzoic acid } \\
& =\frac{\text { mass of crystalline benzoic acid }}{\text { sample mass }} \times 100 \%
\end{aligned}
$$

using the formula above it is obtained that the percentage of the benzoic acid crystals obtained was $5.29 \%$

To the crystals that have been obtained chemical tests and physical tests, where for chemical tests carried out by taking a little crystal of benzoic acid and then dissolved into ethanol, filtered and then into the filtrate obtained added the compound $\mathrm{FeCl} 3$ in ethanol. The result is a yellowish brown solution, which means that the crystal contains benzoic acid. For physical tests carried out by measuring the melting point using melting point apparatus. Determination of the degree of 
soft spot is done by the capillary pipe method, namely witha thermometer and capillary tube are inserted into the melting point device. Then noted the temperature when the sample starts to melt and when the sample melts in its entirety. Point soft is shown by changing the shape of the incense sap from solid to liquid (melts). Changes in the form of incense sap occur at different temperatures in each type. Soft point or melting point is the temperature at which the substance solids form into liquid at a pressure of $1 \mathrm{~atm}$ or temperature when the solid phase and liquid are both in a state of equilibrium. (Sitinjak, H. 2012). From this process the data obtained that the melting point of crystals is in the range $121.2-123{ }^{\circ} \mathrm{C}$.

Subsequent analysis using IR spectroscopy, the following results were obtained:

1. The absorption band in the area of 3100-2700 cm1 (strong peak) shows the presence of the $-\mathrm{OH}$ group of carboxylic acid, which overlaps with aromatic $\mathrm{C}-\mathrm{H}$.

2. The absorption band in the region $1720-1690 \mathrm{~cm}$ 1 (medium peak) shows the presence of $\mathrm{C}=\mathrm{O}$ carboxylic acid groups.

3. The absorption band in the region of $1650-1520$ $\mathrm{cm}-1$ (weak peak) indicates the presence of an aromatic $\mathrm{C}=\mathrm{C}$ group

4. Absorption band in the area of $1275 \mathrm{~cm}-1$ (medium peak) shows the presence of $\mathrm{C}-\mathrm{O}$ from carboxylic acids

5. The absorption band in the region $882.6-715 \mathrm{~cm}-1$ (medium strong peak) indicates the presence of aromatic $\mathrm{C}-\mathrm{H}$ exiting the plane

The results of the analysis use IR spectroscopy as in Figure 1 below.

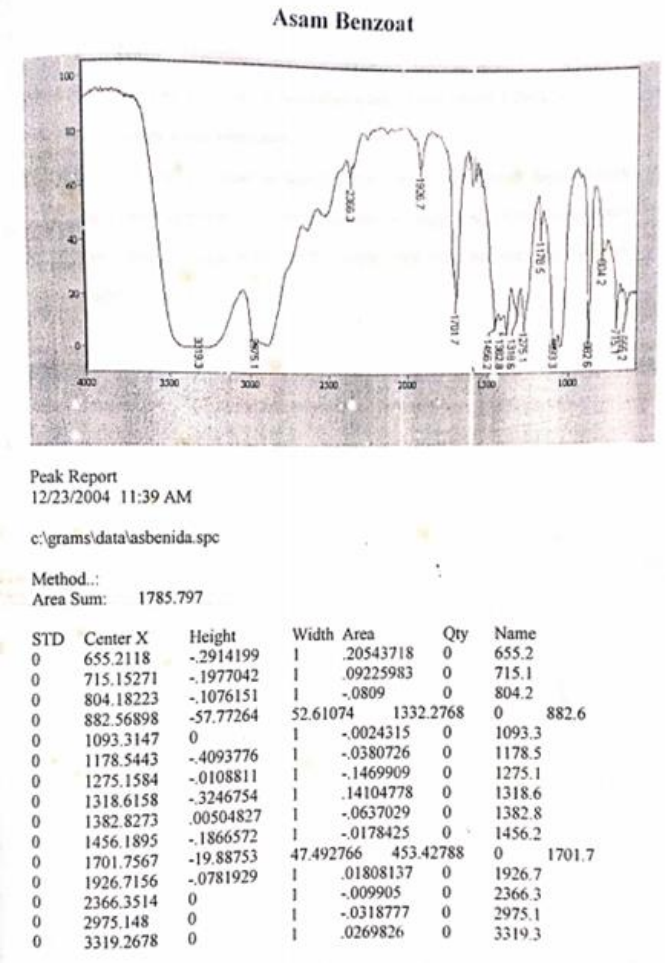

Figure 1. The results of the analysis use IR spectroscopy

\section{CONCLUSIONS}

From this results of the research concluded that:

a. Benzoic acid can be isolated from the sap of incense by saponification or saponification using potassium hydroxide $(\mathrm{KOH})$ solvents in ethanol and hydrolyzed using sulfuric acid (H2SO4) 25\%

b. The percentage of benzoic acid obtained from the isolation results is $5.29 \%$

c. The results of the isolation in the form of white crystals which have a melting point of 121.2-123 $\mathrm{oC}$ with IR spectroscopy test gives a peaking peak at a wavelength of $3100-2700 \mathrm{~cm}-1$ (strong peak), $1700-1690 \mathrm{~cm}-1$ (medium peak), 1650-1520 cm-1 (weak peak), $1275 \mathrm{~cm}-1$ (medium peak and 882.6$715 \mathrm{~cm}-1$ (medium strong peak)

\section{ACKNOWLEDGMENTS}

Thank you to all those who have supported the implementation of this research, especially for incense farmers in the Garoga Village, Garoga District, North Tapanuli Regency, North Sumatra Province 


\section{REFERENCES}

[1] BAPPEDA, 2002. Profil Tanaman Perkebunan di Daerah Tingkat II Tapanuli Utara.

[2] BPS Provinsi Sumatera Utara. Badan Pusat Statistik Provinsi Sumatera Utara. 2008. Sumatera Utara dalam Angka 2008. Medan: BPS Provinsi Sumut

[3] Firdaus, F., Ibrahim, A. A., \& Megawati, W. (2017). Reaksi Cannizaro: Sintesis Benzil Alkohol dan Asam Benzoat.

[4] Jayusman. (2014). Mengenal Pohon Frankincense. Jakarta: IPB Press

[5] Khan, M.L, 2001. Loban (Styrax benzoine). Known as an incense, Loban has multiple benefits even as an medicine. http://www. Islamicvoice.com/march.2001/prophet.htm

[6] Kholibrina, C. R., \& Susilowati, A. (2018, February). Flowering and fruiting phenology of Frankincense toba (Styrax sumatrana JJ Sm.) in AekNauli forest, North Sumatra. In IOP Conference Series: Earth and Environmental Science (Vol. 122, No. 1, p. 012061). IOP Publishing.

[7] Sitinjak, H. 2012. Analisis Sifat Fisika-Kimia Kemenyan (Styrax Sumaterana J.J. SM) Asal Pengururan. Skripsi. Fakultas Kehutanan USU.

[8] Sormin, E., Julianti, K., Nadeak, B., \& Naibaho, L. (2019). Use of construction inquiri learning model to improve the interest of learning students grade XI SMA Angkasa 2 in coloid materials. PEOPLE International Journal of Social Sciences, 5(2), 908-917.

[9] Waluyo, T. K., \& Setiawan, E. (2007). Isolasi Asam Sinamat dari Berbagai Kualitas Frankincense Asal Sumatera Utara. Jurnal Penelitian Hasil Hutan, 25(4), 319-326. Untuk SMA/MA Kelas X. Jakarta: PT. Grasindo. 